\title{
Erratum to dexmedetomidine promotes breast cancer cell migration through Rab11-mediated secretion of exosomal TMPRSS2
}

\author{
Meng Chi ${ }^{1}$, Xiaoding Shi ${ }^{1}$, Xing Huo ${ }^{1}$, Xiaohong Wu ${ }^{1}$, Pinyi Zhang ${ }^{1}$, Guonian Wang ${ }^{1,2}$ \\ ${ }^{1}$ Department of Anesthesiology, Harbin Medical University Cancer Hospital, Harbin, China; ${ }^{2}$ Pain Research Institute of Heilongiiang Academy of \\ Medical Sciences, Harbin, China \\ Correspondence to: Guonian Wang, MD. Department of Anesthesiology, Harbin Medical University Cancer Hospital, 150 Haping Road, Nangang \\ District, Harbin, China. Email: wangguonian609cn@aliyun.com.
}

doi: $10.21037 /$ atm-2020-26

View this article at: http://dx.doi.org/10.21037/atm-2020-26

Erratum to: Ann Transl Med 2020;8:531.

Dexmedetomidine promotes breast cancer cell migration through Rab11-mediated secretion of exosomal TMPRSS2

In the April 2020 issue of Annals of Translational Medicine, the paper "Dexmedetomidine promotes breast cancer cell migration through Rab11-mediated secretion of exosomal TMPRSS2" by Dr. Chi et al. (1) was published with some errors concerning the figures and should be corrected as follow. 
In the left part of Figure 2B, "DEX" was missed and it should be added between "CTL" and "DEX + siCTL" while the legend for Figure $2 B$ remains correct. In Figure $2 C$, the "\#” should be removed, and accordingly the words "\#, $\mathrm{P}<0.05$ " in the figure legend should be deleted. So the Figure $2 B$ and Figure $2 C$ should be corrected as below:
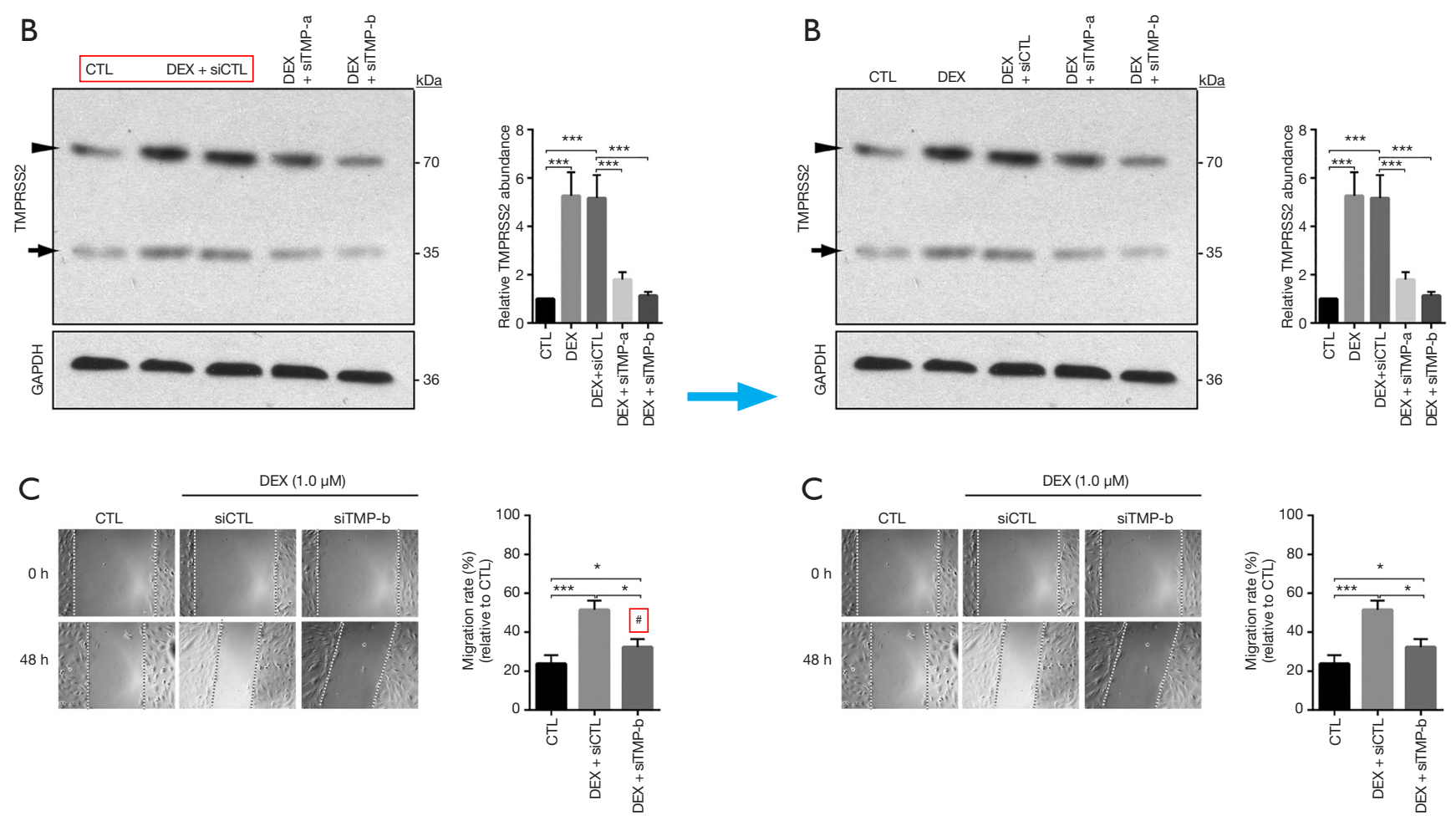

Corrected legend for Figure 2C: (C) Scratch assay was performed in DEX-treated MCF-7 that expressed siTMP-b. DEXinduced increase of migration was prevented by the siTMP-b. Magnification $\times 20$ for all panels. Data are presented as mean \pm SD. The experiment was carried out independently in triplicate. *, $\mathrm{P}<0.05 ;{ }^{* *}, \mathrm{P}<0.01 ;{ }^{* * *}, \mathrm{P}<0.001$. 
In Figure 3E, the "\#\#” should be removed from the left graph and the words "\#\#, $\mathrm{P}<0.01$ ” in the figure legend should be accordingly deleted. So the Figure $3 E$ should be corrected as below:
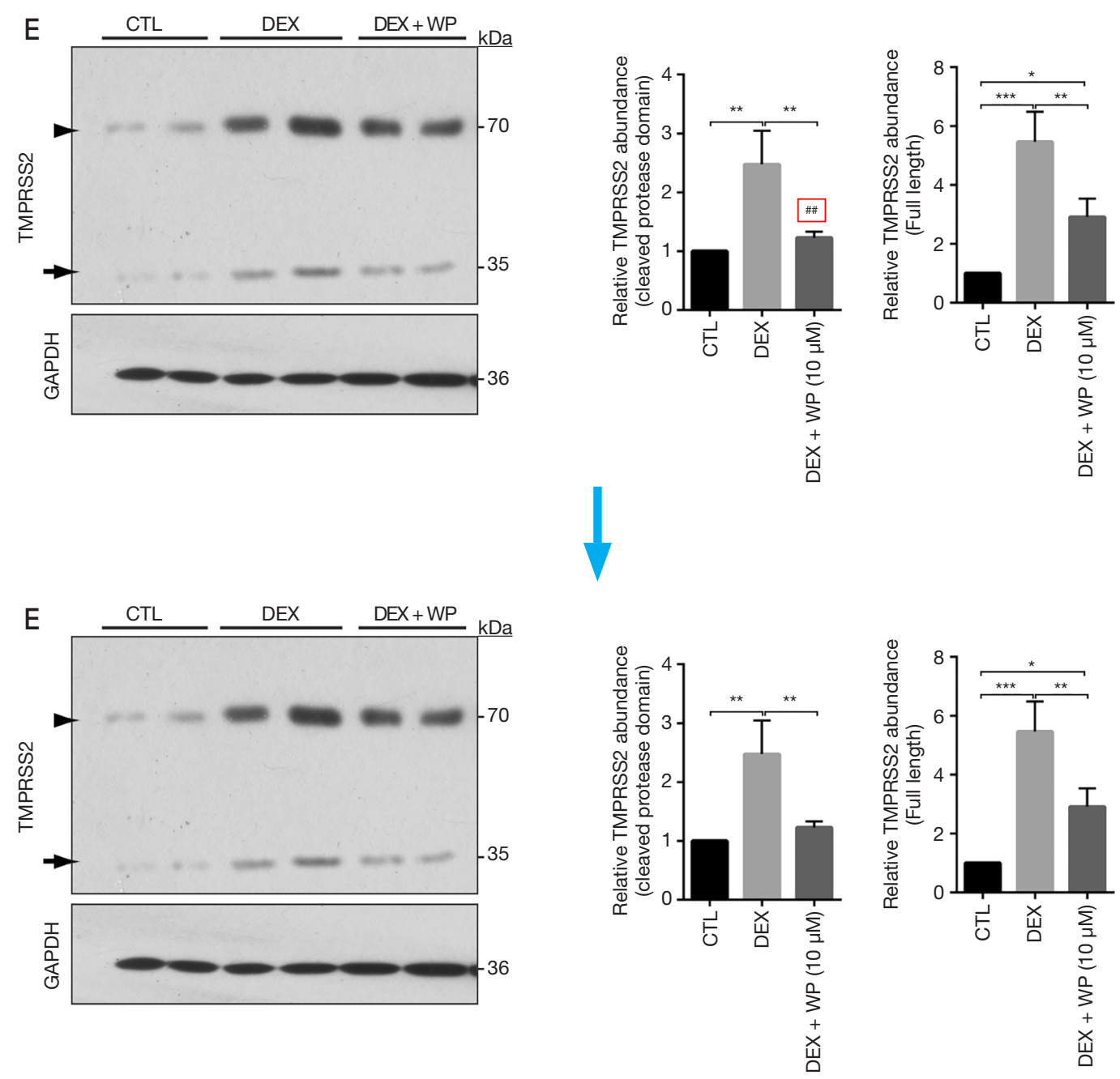

Corrected legend for Figure 3E: (E) MCF-7 was pretreated for $1 \mathrm{~h}$ with $10 \mu \mathrm{M}$ of WP1066 followed by incubation for $48 \mathrm{~h}$ with $1 \mu \mathrm{M}$ of DEX. Total cellular protein was extracted, and Western blot assay was performed to detect the expressions of full-length (arrowhead) and the cleaved protease domain (arrow) of TMPRSS2. Data are presented as the mean \pm SD. The experiment was conducted independently in triplicate. *, $\mathrm{P}<0.05 ;{ }^{* *}, \mathrm{P}<0.01$; ${ }^{* *}, \mathrm{P}<0.001$. 
In Figure 4B, the “***” was missed in the middle graph and it has been added. So, the Figure $4 B$ should be corrected as below:
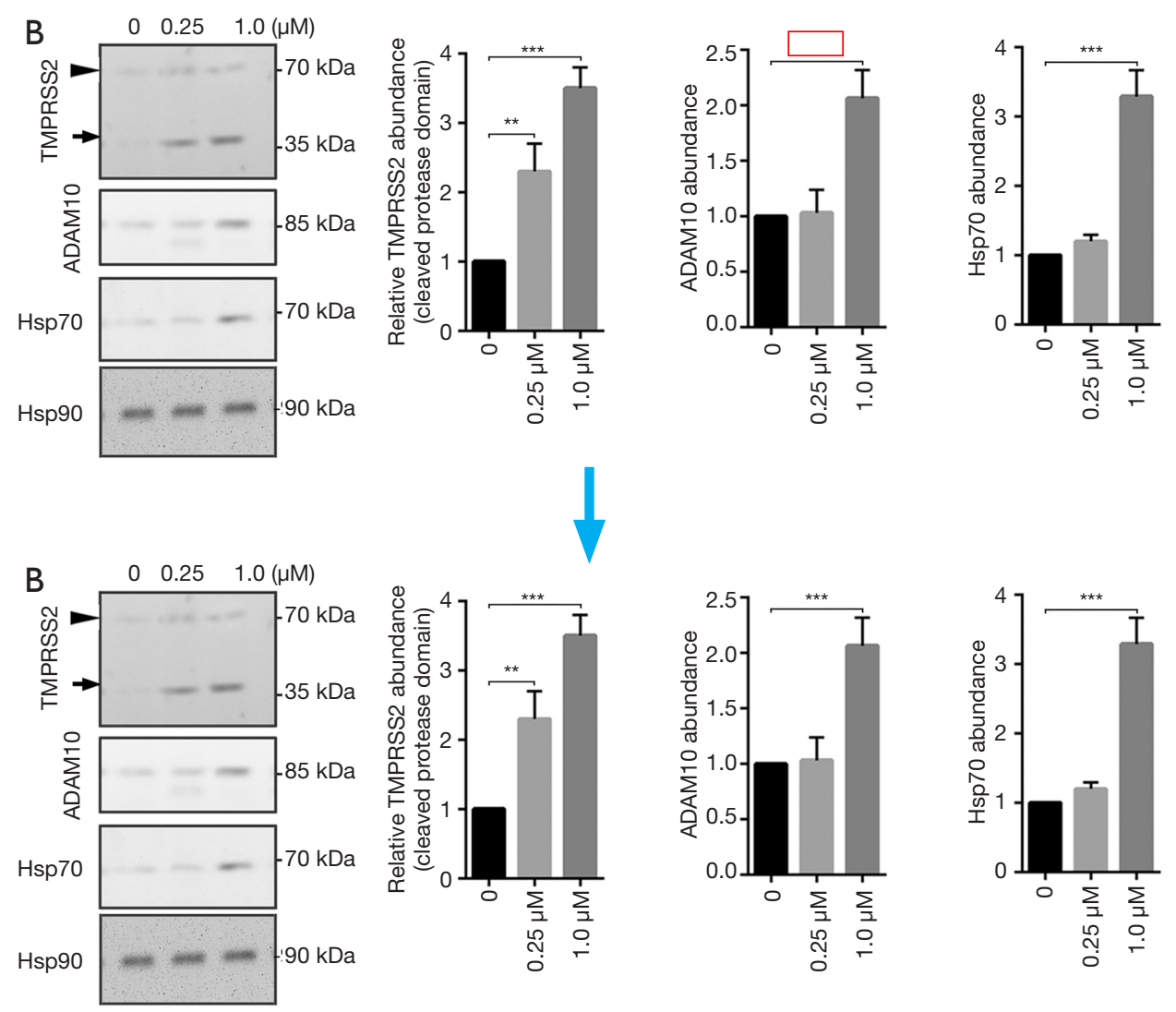
In Figure S3B, the blot for TMPRSS2 in the Cell lysates fraction was missed and it has been added. So the Figure S3B should be corrected as below:
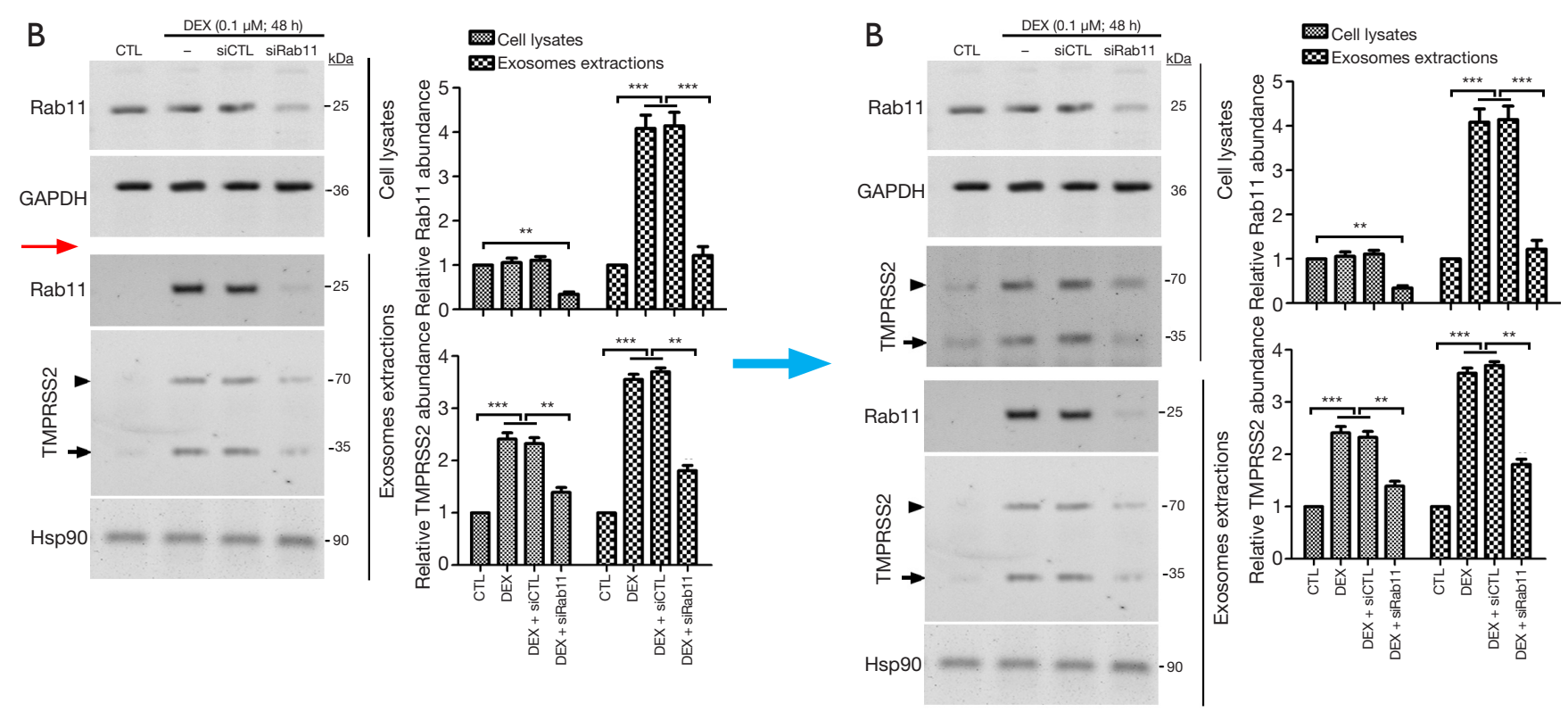

The authors regret the errors and all inconveniences caused.

Open Access Statement: This is an Open Access article distributed in accordance with the Creative Commons AttributionNonCommercial-NoDerivs 4.0 International License (CC BY-NC-ND 4.0), which permits the non-commercial replication and distribution of the article with the strict proviso that no changes or edits are made and the original work is properly cited (including links to both the formal publication through the relevant DOI and the license). See: https://creativecommons.org/licenses/by-nc$\mathrm{nd} / 4.0 /$.

\section{References}

1. Chi M, Shi X, Huo X, et al. Dexmedetomidine promotes breast cancer cell migration through Rab11-mediated secretion of exosomal TMPRSS2. Ann Transl Med 2020;8:531.

Cite this article as: Chi M, Shi $\mathrm{X}$, Huo $\mathrm{X}, \mathrm{Wu} \mathrm{X}$, Zhang $\mathrm{P}$, Wang G. Erratum to dexmedetomidine promotes breast cancer cell migration through Rab11-mediated secretion of exosomal TMPRSS2. Ann Transl Med 2020;8(16):1040. doi: 10.21037/ atm-2020-26 